\title{
TAKING E-MODERATING SKILLS TO THE NEXT LEVEL: REFLECTING ON THE DESIGN OF CONFERENCING ENVIRONMENTS
}

\author{
Shelagh M. Ross \\ s.m.ross@open.ac.uk \\ Department of Physics and Astronomy \\ The Open University, Walton Hall, Milton Keynes, MK7 6AA \\ http://www3.open.ac.uk/science/physics/people/person/143.htm
}

Agnes Kukulska-Hulme

a.m.kukulska-hulme@open.ac.uk

Institute of Educational Technology

The Open University, Walton Hall, Milton Keynes, MK7 6AA

http://iet.open.ac.uk/pp/a.m.kukulska-hulme/agnes.html

Helen Chappel

hchappel@hol.gr

SCROLLA

University of Glasgow, 53 Hillhead Street, Glasgow G12 8QQ

Brian Joyce

brian.joyce@1sc-opisto.fi

LSC-Opisto

Näsilinnankatu 22 A 34, 33210 Tampere, Finland

\begin{abstract}
This paper reports an analysis of computer conference structures set up for a distance education course in which major components of the teaching and learning involve group discussions and collaboration via asynchronous text-based conferencing. As well as adopting traditional e-moderator roles, tutors were required to design appropriate online spaces and navigation routes for students. Tutors' views concerning conference structures focussed on tensions between enabling easy access to conference areas, facilitating the successful running of activities, and addressing students' subsequent needs for retrieval of conference material for assessment tasks. The geographically dispersed course tutors initially explored these issues in reflective online conversations. Comparisons were made between structures that were set up differently but all used for essentially the same tasks and purposes. Evidence from conference messages, from student feedback given in questionnaire and interview responses, as well as from students' written assignments, provided insights into the impact such structures may have on the student learning experience. Students found conference areas for their own group easy to navigate, but they had concerns about managing the large number of messages; these concerns centred on the volume, threading, linking, length, and language of messages.
\end{abstract}




\section{KEY WORDS}

Networked learning environments, collaborative learning, online tutoring, virtual spaces, message threading, reflective practice

\section{INTRODUCTION}

The increasing use of online learning activities and asynchronous conferencing is bringing new dimensions to open and distance learning (ODL), with pedagogy and course support evolving to take advantage of new affordances. When online collaboration is an essential element of a course, such that the group activities are themselves both a forum for personal development and a study resource, the distinction between course design and learner support is blurred [1]. In such a system, tutors have to move beyond their traditional ODL role of supporting a fixed set of course material [2] into new areas that combine subject and process expertise. In recent years there has been considerable interest in the use of asynchronous, text-based, networked environments for collaborative learning tasks. Analyses have typically been concerned with either the behaviour of the learners and the nature of their online interactions, including those by Jones [3]; Noakes [4]; McKenzie and Murphy [5]; Curtis and Lawson [6], or the competencies required by e-moderators [7]. However, rather less detailed attention has been paid to the design of the conferencing environments themselves, although Cox [8] considered this aspect among others affecting student experience.

Goodyear $[9,10]$ maintains that it is not really possible to create, or even to manage, a learning community from the outside. The best that can be done is first to design tasks that guide students actively to construct their own knowledge and, secondly, to design the learning spaces and places in ways that are compatible with the learning tasks. Goodyear [9] defines virtual spaces as "local habitations for individual learners or for learning communities. Such spaces are the embryonic physical manifestation of the learning environment, in all its nested complexity," and characterizes place with respect to "all those attributes of a particular space that make it unique and that differentiate it from other places."

Many virtual e-learning environments make use of analogies to familiar kinds of buildings and spaces, for example campuses, libraries, and cafés. Cicognani [11] and Goodyear [9] have used architecture as a model for the design of online spaces, noting key similarities such as the organisation of the space by function, the relationship between use and access, and the manner in which users of the space acquire ownership, become comfortable in navigating and living in the built space and may ultimately modify it for their own purposes in ways not envisaged by the original architect. As Goodyear [9] puts it, "architecture is about the crafting of affordances."

Putz and Arnold [12] have noted that learning in online communities "is emergent and cannot be designed," since an online community of practice is fundamentally a self-organizing system. The design of an online seminar never completely determines the learning practices: "Instead, the learners make use of the learning architecture as one element in a series of resources and develop their own responses to it" [12]. Putz and Arnold conclude that research effort should be directed towards a better understanding of the actual learning practice of students as a response to various online learning architectures.

This paper discusses how the requirement for tutors to design, scaffold, and moderate group activities online brings with it the need for them to consider the structure of the conference spaces in which these activities take place. We describe an investigation that explored the perspectives of both tutors and students, seeking to discover and understand their priorities and behaviours. The context of the specific course and online environment they were working in is presented, followed by an analysis and discussion 
of data from several different sources.

\section{CONTEXT}

\section{A. The course}

The course taken here as a case study, Applications of Information Technology in Open and Distance Education, is a module of the postgraduate Masters in Open and Distance Education offered over the Internet to a world-wide audience by the UK Open University. In the cohort discussed here, there were 66 registered students, distributed among five tutors. The course is designed as an eight month exploration of: information and communication technologies (ICT) in distance education (Block 1), Web-based teaching and learning (Block 2), interactive educational multimedia (Block 3), and the theoretical base for the above applications (Block 4). As such, it provides both examples of a variety of online activities and a pool of students and tutors professionally engaged in the field, whose discussions of the nature of such activities form part of the course.

Although a large package of resources is supplied (set books, printed course notes, audio, video, multimedia examples on CD-ROM, and a software program for multimedia authoring), the Study Guides are provided via the course website and the bulk of the course is constructed by the participants through online discussions and group-work. There is a major focus on collaborative work in small groups, with specially designed activities during which students interact with peers and tutors in the conferences. There is a continual emphasis in these activities on students building and sharing their own understanding, grounded in their own professional practice as well as in their experience as learners. The socialconstructivist learning philosophy of the course expects students not only to use the conference activities for discussion, but also to regard the record of conference messages as an important element of the resource base. The assessment strategy requires them to include extracts from and references to the online discussion in their assignments, both as an encouragement to active online involvement and as a reward for participation.

\section{B. The conferencing environment}

\section{Large scale structure}

The asynchronous conferences and, to a much lesser extent, e-mail exchanges provide the day-to-day fora in which learning interactions take place. FirstClass ${ }^{\mathrm{TM}}$ is currently the standard e-mail and asynchronous conferencing package offered to all students of the University. For this cohort, version 5.611 was in use. A Web version of FirstClass was used throughout by a small minority of students, but this had reduced functionality, so tutors were required, and most students chose, to install the client software. (Screenshots presented in this paper are therefore from client displays.) Those using the client software had the additional option of installing an offline reader, FirstClass Personal.

Figure 1 illustrates the top level of the course conference structure: this consists of a notice board for administrative messages, a technical self-help area, a specialist library (Ask ICDL) for the retrieval of electronic resources, a plenary hall for discussions among all course participants, and separate areas for each of the five Tutor Groups. Deeper structures are progressively revealed as one enters conference areas: for example, clicking on the Plenary icon would download a list of the messages posted to that particular conference, but would also bring up the next layer of spaces within it: a café, an area for special events such as seminars led by external experts, and other whole community spaces. Having once reached a given conference by working down the structures from the top level to reach it, users may then, if they 
wish, drag its icon to their FirstClass desktop to create a shortcut.

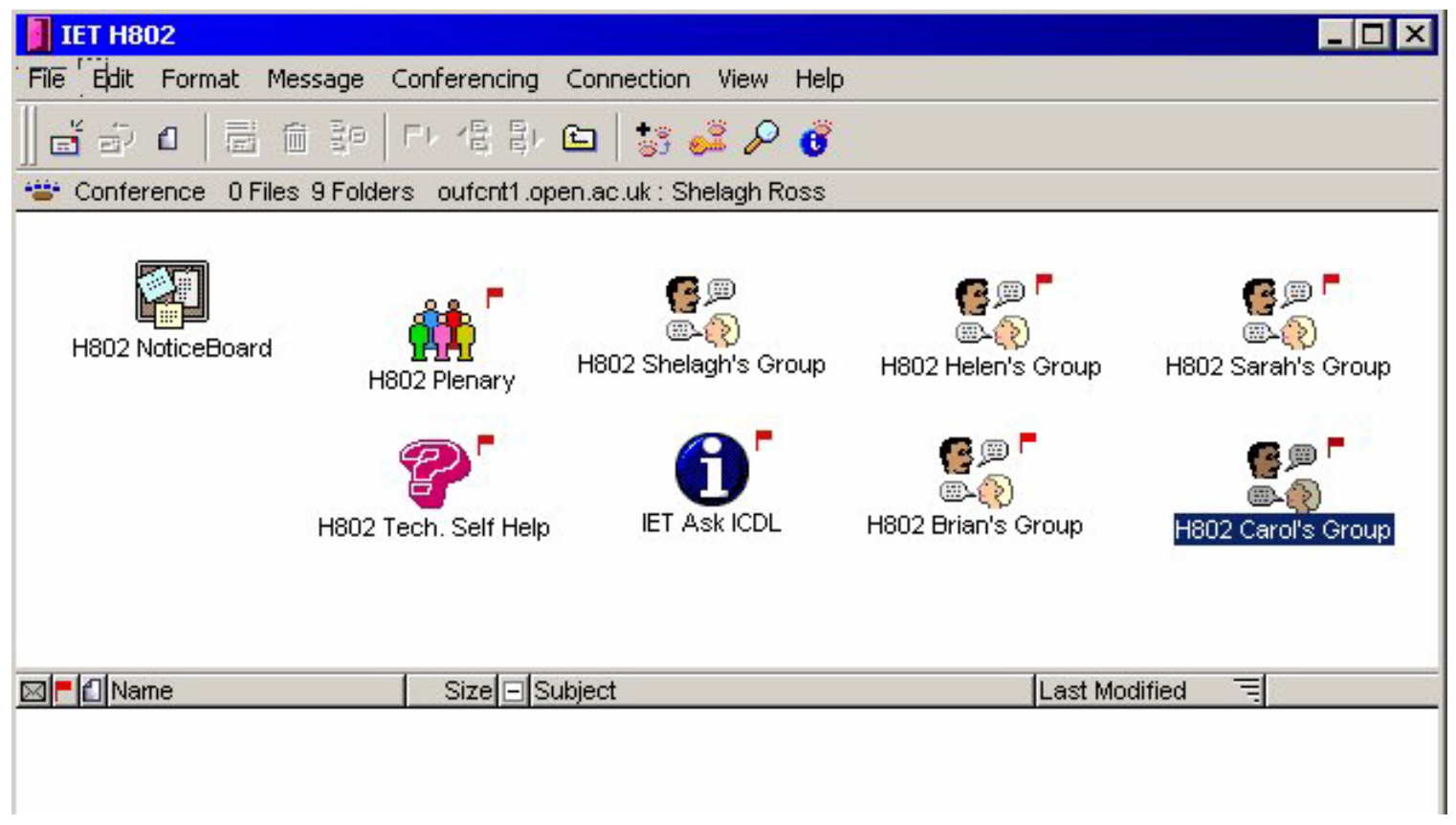

Figure 1: The top level of the course conference structure

All tutors have exclusive control of their own areas, and only they can create conferences within it; other areas are centrally maintained. The University system backs up and is responsible for the maintenance of the entire conference record. For the first six months of the course, the Tutor Group conferences provide the focus for the activities, in which students work collaboratively to carry out knowledge-building tasks. The online activities for the final two months are mostly carried out in the Plenary area.

\section{Working in the conference spaces}

All students and tutors have access to all the Tutor Group areas, and students are positively encouraged to look at what is happening in groups other than their own; course etiquette, however, strongly discourages cross-group posting. This process, first developed by one of the authors of this paper (Helen Chappel) while herself a student on an earlier version of the course, was labelled super-lurking, as opposed to the more usual term of lurking for reading but not contributing, which tends to have pejorative overtones. Although other authors (such as McKenree and Mayes [13]) have discussed the learning benefits gained by observing peer learners online, super-lurking takes such observation a stage further. The terminology is intended to imply not only that it is an acceptable practice, but also that it is done with a specific purpose: that of surveying discussion in other groups not only to see other possible approaches, pick up useful references, and make comparisons, but also to report these back and inform further discussion in one's own group.

When users download a particular conference, they obtain a list of the headings or subject lines of the individual messages, with unread messages marked by red flags. (The content of an individual message is transferred from the server only when the message is opened.) Figure 2 shows an example of a message thread in the Tutors' Conference, an area reserved for tutor-only interactions. The user can customise the view; in this case, the messages are sorted chronologically. There is an option to group messages by subject, and discussion threads can be opened or collapsed. All messages except the first are indented, but 
there is only one level of indentation, and the structure of the thread must be deduced from the numbering system. This is not always possible without careful analysis of the chronology or even content of messages. System tools (Next in thread and previous in thread buttons on the toolbar) provide some assistance with navigation in complex threads.

\begin{tabular}{|c|c|c|c|c|c|c|}
\hline & rchived & ssages & & & & 짐 \\
\hline & Et lit Fo & nat Message & Conferencing & Connection View Help & & \\
\hline 푸 & $\square 0$ & 㢄: 血晤 & 所倡 是 & 包 $\mid \begin{array}{ll}\text { sin } & \theta\end{array}$ & & \\
\hline$\sqsupset \mathrm{Fo}$ & Folder 88 & iles 0 Folders & outcnt1 .open. & c.uk: Shelagh Ross & 밈 $\theta$ & $8=$ \\
\hline 国F & DName & & Size $⿴ 囗 \mathrm{~S}$ & dbject & Last Modified & $\Delta$ \\
\hline 两 & Shelag & Ross & $2 \mathrm{~K} \boxminus \mathrm{C}$ & onference structures & $04,06 / 2001 \quad 19: 59$ & \\
\hline$凶$ & Brian J & yce & $3 K$ & Re: conference structures & $05 / 06 / 2001 \quad 11: 05$ & \\
\hline 凶 & Carol 1 & ggison 2 & $4 K$ & $\operatorname{Re}(2)$ : conference structures & $05 / 06 / 2001 \quad 19: 40$ & \\
\hline$凶$ & Helen $\mathrm{C}$ & happel-Hayios & $4 \mathrm{~K}$ & Re: conference structures & 06:06/2001 04:07 & \\
\hline 四 & Helen & happel-Hayios & $3 \mathrm{~K}$ & $\operatorname{Re}(2)$ : conference structures & $06 / 06 / 200107: 54$ & \\
\hline 凶 & Agnes & Cukulska Hulme & $3 K$ & $\operatorname{Re}(3)$ : conference structures & $08 / 06 / 2001 \quad 11: 35$ & \\
\hline 凶 & Brian J & yce & $3 \mathrm{~K}$ & $\operatorname{Re}(4)$ : conference structures & $08 / 06 / 2001 \quad 16: 19$ & \\
\hline$凶$ & Carol H & ggison 2 & $3 \mathrm{~K}$ & $\operatorname{Re}(5)$ : conference structures & $09 / 06 / 2001 \quad 17: 33$ & \\
\hline 四 & Shelag & Ross & $8 \mathrm{~K}$ & Re(4):structuresi rationale & $09 / 06 / 200121: 02$ & \\
\hline 凶 & Helen & happel-Hayios & $4 \mathrm{~K}$ & $\operatorname{Re}(5)$ : structuresi rationale & $10,06 / 200103: 58$ & \\
\hline 凶 & Brian J & yce & $7 K$ & $\operatorname{Re}(5)$ : tructuresi rationale & $10 / 06 / 200108: 43$ & \\
\hline 凶 & Carol H & ggison 2 & $7 K$ & Re(6): tructures/ rationale & $10,06 / 2001 \quad 17: 50$ & \\
\hline 四 & Shelag & Ross & $3 K$ & Re(6): structuresi rationale & $10 / 06 / 2001 \quad 19: 47$ & \\
\hline 凶 & Shelag & Ross & $2 \mathrm{~K}$ & Re(6): tructuresi rationale & $10,06 / 2001 \quad 19: 53$ & \\
\hline 凶 & Helen & happel-Hayios & $2 \mathrm{~K}$ & Re(7): structures/ rationale & $11,06 / 200100: 54$ & \\
\hline 四 & Carol H & ggison 2 & $3 \mathrm{~K}$ & $\operatorname{Re}(7)$ : structuresi rationale & $12,06 / 200109: 34$ & \\
\hline 四 & Helen & happel-Hayios & $2 \mathrm{~K}$ & Re(8): structuresi rationale & 13:06/2001 01:03 & \\
\hline 四 & Brian J & yce & $4 \mathrm{~K}$ & $\operatorname{Re}(9)$ : structuresi rationale & 13,06/2001 08:08 & \\
\hline 四 & Shelag & Ross & $2 \mathrm{~K}$ & Re(10): structuresi routes & $13 / 06 / 2001 \quad 10: 13$ & \\
\hline 凶 & Helen & happel-Hayios & $3 K$ & Re(11): structuresi routes & $15,06 / 200109: 54$ & \\
\hline 四 & Sarah & Cornelius & $2 \mathrm{~K}$ & Re(12): structuresi routes & 18:06/2001 20:11 & \\
\hline 凶 & D Sarah & Cornelius & $24 K$ & $\operatorname{Re}(2)$ : conference structures & $04 / 07 / 2001 \quad 12: 13$ & \\
\hline 凶 & Shelag & Ross & $8 K \boxminus p$ & oposal & $18,06 / 200108: 36$ & $\nabla$ \\
\hline
\end{tabular}

Figure 2: Message thread within the tutors' conference

As Hewitt [14] has noted, threaded discourse, in which one message can only reply to one other message, is prone to subject drift. One contributor originates a thought, another person replies but in doing so partly or wholly changes the subject, perhaps by using the feature that enables a small portion of one message to be highlighted and set out in quotation as the base for a response. In the FirstClass environment, it is very easy simply to continue using the reply facility — with its default subject line-despite the conversation moving on in this way, so that the subject line of later messages may end up bearing little relation to their content. This default subject line can quite easily be modified, as was done twice within the thread in Figure 2. However, most tutors and learners failed to sustain such practice, despite periodic prompts and agreements to do so. A particular problem with hierarchical threading arises from the fact that it is not possible to reply to more than one message at a time; this makes it difficult to have a general conversation, let alone a convergent discourse. Two FirstClass system tools-hotlinking and summarizing — can provide at least partial solutions:

- Hotlinking is achieved by dragging a message subject line into the text of one's own message; this automatically creates a link to the earlier message. However, such links only work with the 
client software and require that the user has not entered either via a shortcut to the conference or via the offline reader.

- Summarizing can be done by using a feature of FirstClass whereby a new document is created containing the full text of whichever messages the user selects. This text can then be saved and edited as required. The edited version can then be posted as a new message to show the relationship between the original set of messages.

Both the hotlinking and summarizing features can be useful in drawing in messages that have mistakenly been submitted unthreaded, despite actually contributing to an ongoing discussion: as Kear [15 (2001)] has pointed out, breakage or poor use of threading can otherwise play havoc with an entire discussion.

Although the messaging system in FirstClass conferences looks much like e-mail, there are many graphic elements that can give visual clues to help navigation. Conferences can be arranged spatially; conferences, and even individual messages, can be given appropriate icons; within messages the sizes and colours of fonts can be varied and artwork inserted. (For students using the Web version of FirstClass hotlinks could also be incorporated into graphics.) The message illustrated in Figure 3 illustrates a tutor's use of graphics to help with pacing. This particular message introduced the first group activity and was modified by the tutor as the activity progressed. At the stage shown here, the time slot for the main phase of the activity had passed, but the students were being encouraged to continue their discussion in the Reflect 3 area until the due date for the tutor-marked assignment (TMA01).

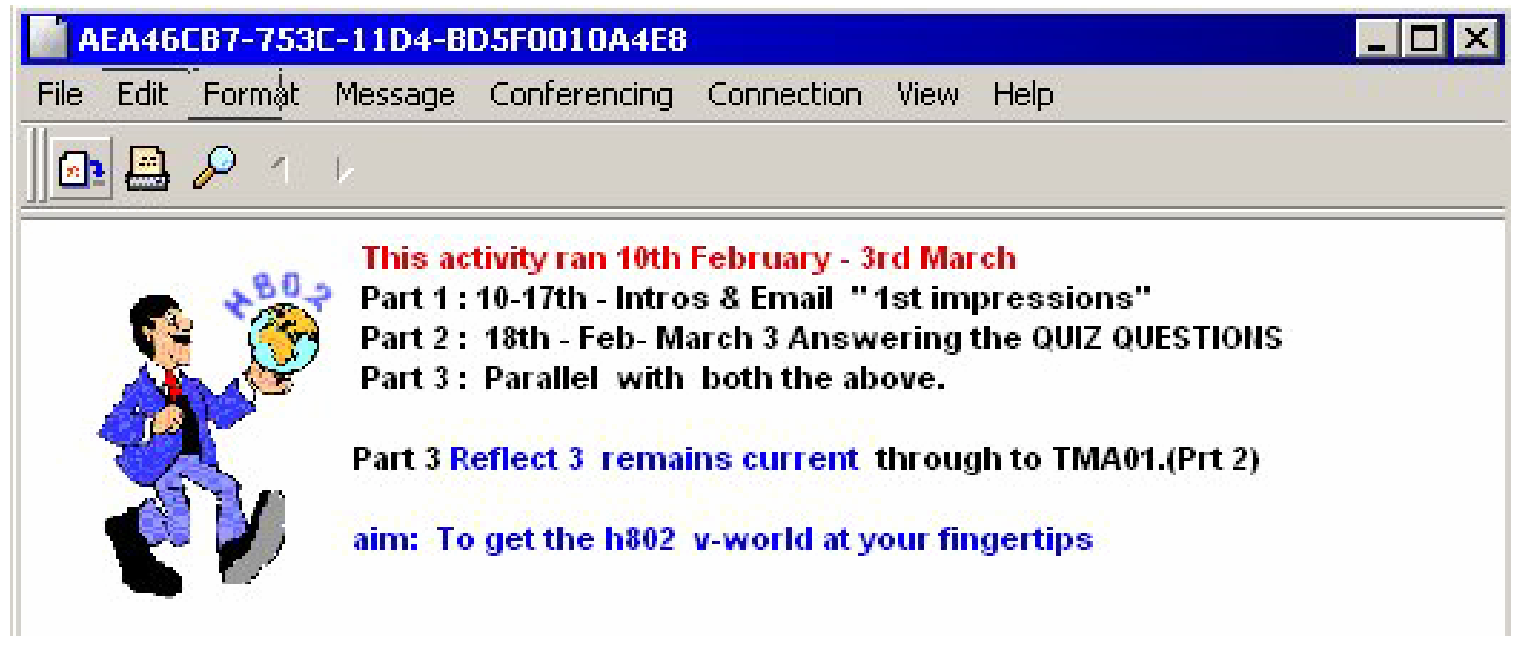

Figure 3: Graphics within a tutor's message

\section{The tutors and the Tutor Group conferences}

\section{The role of the tutors}

Goodyear [16 (1999)] has laid out a pedagogical framework for research projects in ODL that categorizes the structure of learning environments in terms of four ordered elements: philosophy, high level pedagogy, strategy and tactics. Describing the course in terms of this framework is useful in situating the role of the tutors and the scope of the project reported here. The declarative or conceptual elements of philosophy (social-constructivist and learner centred, but also informed by community practice) and higher level pedagogy (resource-based learning, collaborative activities and learning by doing) are set by the Course Team who choose the key resources and prepare the assessment material for each presentation 
of the course. The operational layers of strategy and tactics, on the other hand, are to a large extent controlled on a day-to-day basis by the tutors, each of whom has a relatively free hand to construct the learning environment within the conferences for their individual group of students, although suggestions are provided by the Course Team.

In Goodyear's scheme, strategy in the construction of the learning environment is characterised as actions and intentions at a level above that of specific tactics. For the tutors in this course, strategy encompassed intentions such as creating a safe learning environment within the conferences, encouraging participation, promoting collaboration and mutual support, helping students to develop particular skills, fostering a high level of academic debate, and building up a body of work that could be used subsequently as a useful group resource. Goodyear describes tactics as "the detailed moves through which strategy is effected [16]." Here, the tutors' tactics would cover such things as the creation of separate spaces within the conferencing areas (and the number, hierarchy and naming of those spaces), allocation of students to subgroups, negotiation with students about the way activities are run, appointment of student moderators for some activities, posting of summaries, decisions about how to handle students who transgress accepted rules of behaviour, and choice of methods for giving encouragement to students who appear to be struggling or are not posting in the conferences.

\section{The tutors and their groups}

The five tutors, coded A-E in this paper, varied considerably in their background and experience. Two (A $\& \mathrm{~B})$ were new to the role, the other three $(\mathrm{C}, \mathrm{D} \& \mathrm{E})$ were teaching the course for the second successive year, although the previous presentation had used a different conferencing system. Two (A \& C) were themselves graduates of the programme. Only one (E) had previous experience of the FirstClass environment, having used this extensively for conferencing on three other courses. Specific training was provided for the tutors, and the tutor conference was active ahead of the course start date to allow familiarization with aspects of the course and with the FirstClass system.

Each of the five tutors had a group of 12-15 students, which they sometimes sub-divided into teams for different activities. By about the halfway point of the course, it became apparent that each of the five tutors was making creative use of their relative freedom to set up their conference structures in ways that seemed most appropriate to them, and that a wide variety of practice and complexity was resulting. The most obvious manifestation of this diversity was architectural, as evidenced by the numbers of subconferences created by each tutor. Two examples are shown in Figure 4 . The entry level is the one reached by clicking on one of the Tutor Group icons at the top (course) level shown on Figure 1. In the representation in Figure 4, each conference that contained sub-conferences is shown within a solid box. These boxes have been unpacked in the figure for a single Block 1 activity-activity 2, which is an online debate. Tutor A set up this activity at level 2, with a total of five sub-areas at levels 3 and 4 . Tutor E set it up at the entry level, with one area for each team at level 2 and no further sub-areas.

The tutors have to design and manage the conference areas to fulfil several purposes-as areas for current work with their own student group, as places where students from other groups may super-lurk, and as resources to which students may return after the activity is completed in order to find specific material for assessed assignments. However, the primary requirement is for an environment in which the tutor's own students can successfully undertake the immediate work associated with each successive activity, work that may involve a large number of messages. For example, during the four weeks allocated to the activity 2 highlighted in Figure 4, the six students in Team A of Tutor E's group generated 290 messages and the six students in Team B generated 275. Some tutors therefore felt the need for sub-structures to help students keep track of a particular discussion while it was ongoing. Some tutors were also very conscious 
of using structure to aid retrieval of key messages at later stages of the course, when the total number of messages would have mounted to between 1000 and 2000 in each tutor group.

\section{$\underline{\text { Tutor A }}$}

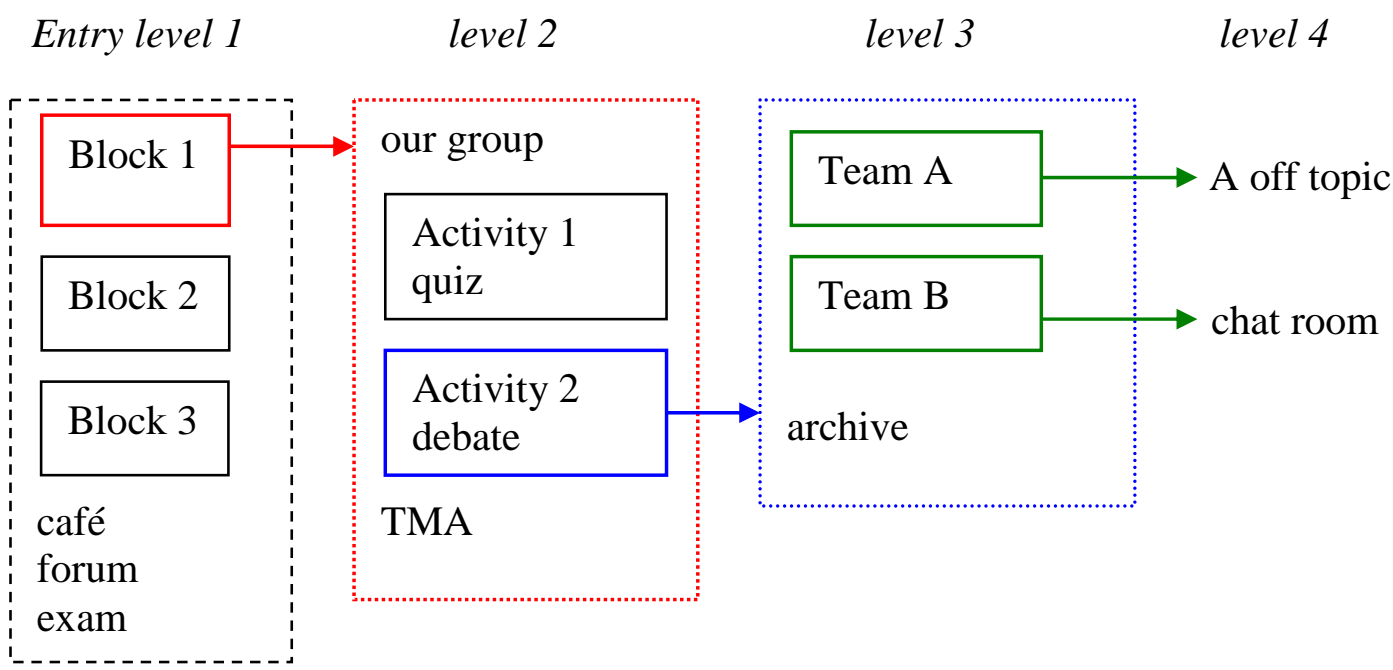

\section{$\underline{\text { Tutor E }}$}

Entry level $1 \quad$ level 2

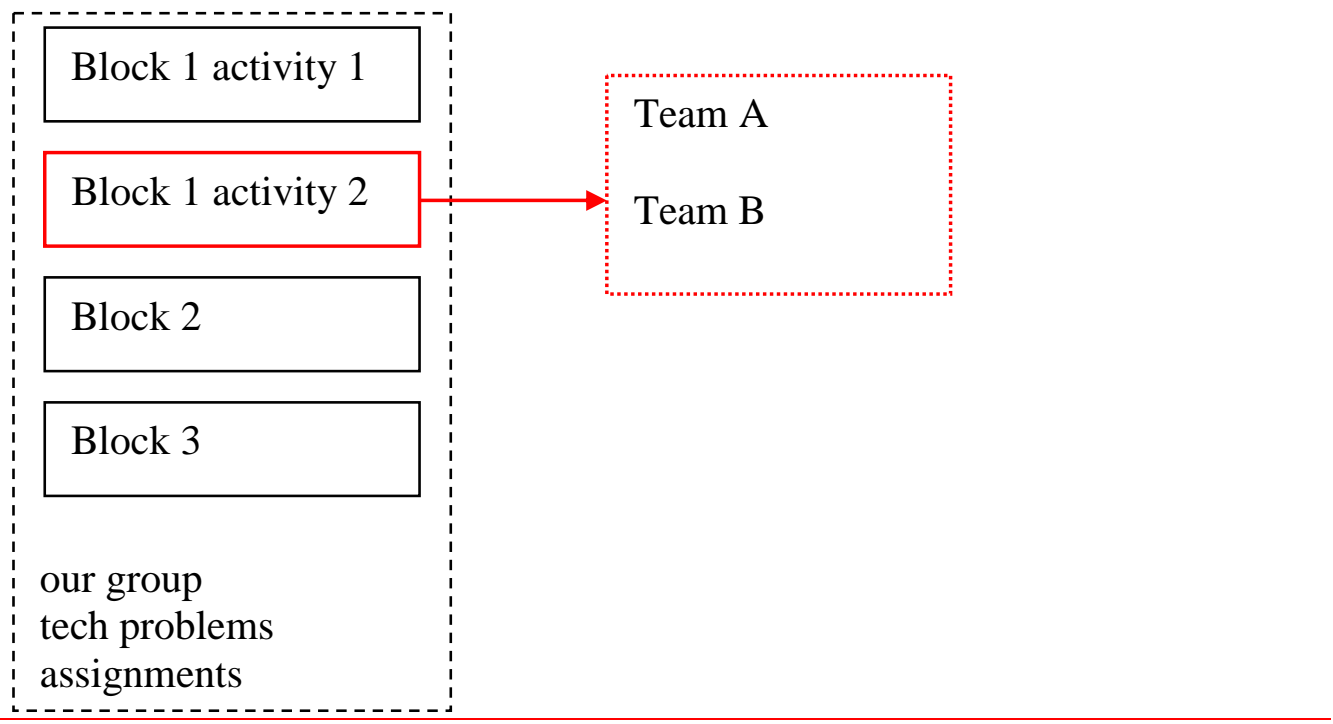

Figure 4: Examples of conference architecture

Differences in both the number of levels used and the number of separate conferences spaces created became very evident as the course progressed. By the end of the course, Tutor $\mathrm{C}$, who set up the most complex structures, had created 54 conferences using up to 4 levels. In the same period, Tutor E, who used the simplest structures, created only 19 conferences and had never used more than 2 levels. The other tutors had each created around 40 conferences, though Tutor D had on occasion used 5 levels. A 
comment was made in the tutors' conference noting this diversity and the ensuing discussion gradually broadened into articulations of strategies, tactics, and priorities. This sowed the seed for an exploration of the reasons for, and effects of, diversity at the operational levels.

\section{TUTOR PERSPECTIVES}

The initial discussion of the issues developed in response to a comment from one of the tutors, but all five tutors and the Course Team chair then contributed to a sustained and open reflection on their practice. The discussion gradually evolved to include elements of an action research approach, but was mainly seen as a process of experimentation, sharing, and reflection, and was certainly not an attempt to devise a one size fits all prescription of practice. The discussion in the tutors' conference ran to about 65 messages, spread over a period of three months, and further elucidation was subsequently sought by e-mail.

This sharing of perspectives among the tutors led to the formalization of a set of research questions, formulated in Section IV, which guided the later investigation of student perspectives.

All five tutors followed the basic advice given to them by the Course Team that they should map their conferences on to the overall Block structure of the course and that they should create a conference for each separate activity. As Tutor B said:

a conference for each activity... focuses the students' attention in one place for the duration of the activity[;] moving to a new conference clearly marks the beginning of a new task.

However, this argument for a focus in one place became far less strong when viewed against the actual number and arrangement of sub-conferences. In many groups, this one place marked the entry point for an activity, but the actual tasks might be carried out in a number of separate rooms within that space. It was clear that the tutors' ways of structuring their group areas were strongly influenced by their priorities and previous online experiences. This brought into sharp focus the tensions between the various purposes of the conference areas, since as soon as the tutors began to articulate the rationales behind the structures they had set up it became apparent that they had different issues uppermost in their minds when designing their conference areas. The issues that emerged can be clustered around four themes:

- enabling access and navigation

- sustaining productive discussion

- creating a usable resource

- developing a social dimension.

Each theme is expanded upon below.

\section{A. Enabling access and navigation}

Only Tutor E gave ease of access and navigation top priority, and this was one of the main reasons for the relative simplicity of her conference structures. She assumed that students would normally go in at the top level and work down the levels to the conference they needed (this being essential if they wanted to insert hotlinks to other messages into their own contributions). She wanted them to reach the current conference with as few mouse clicks as possible, since each click corresponds to a process of downloading a message list and opens another window on screen. Mainly for this reason, tutor E tried to keep down the number of layers in her structures. Tutor B also commented that a multitude of open windows could be confusing 
and stated that this fact in particular had led her to try to reduce the amount of nesting in her structures.

Tutor E felt that an architecture with few layers would be welcomed by students using the offline reader FirstClass Personal, who have to make an alias for every conference to get it to replicate, and by those from other groups super-lurking in her conference. At a later point in the tutors' discussion, however, Tutor E commented:

On reflection, the point about downloads is maybe slightly a question of swings and roundabouts: does it take longer to download lots of small conferences than one large one? Probably not, though to me it always just feels a bit more irritating.

However the tutors who designed more complex structures were also concerned about navigation. Several created portal conferences, which were intended not as interactive areas but as places for the tutor to post messages associated with basic information or updating and to provide a way in to the nested structures.

Some tutors were also skilled in constructing graphic representations as aids to navigation. Tutor C, whose architecture for the debate activity discussed in Figure 4 contained a total of 8 conferences at levels 3 and 4, provided a map to illustrate part of the nested structures for this activity and a diagram to show the ways in which the student roles related to these structures. While the hotlinking associated with maps in the web version could not be replicated in the FirstClass client, these graphics nevertheless gave a clear picture of the architecture of the conference spaces. Tutor E commented on how C's more extensive experience of site maps for Web-based interfaces might have influenced her in this direction and continued by saying that:

mulling over [C's] map has brought home to me another aspect of the FirstClass client view. A complicated structure really does need a ... map in order to fix a picture of the area in one's head. ... Was it the lack of a visual map that pushed me towards the simple structures-or did I not feel the lack of a map precisely because the structures were simple?

\section{B. Sustaining productive discussion}

It is difficult to over-emphasise the extent to which this course is built anew by each cohort of learners through their shared activities within the conferences. Reflection on this experience, as well as on the content of individual messages, is an integral part of the learning, and is rewarded in the assessment. The issue of fostering the discourse is therefore very much entwined with that of subsequent retrieval of key messages, which is discussed in the next subsection. The tutors again tended to have different positions on how best to approach these issues from the structural point of view.

Tutor C's complex structures arose mainly from her strongly held belief that conferences should not be seen simply as containers for messages, but as a means of conceptual organisation of information. For her, therefore, "design decisions [are de facto] cognitive ones . . intrinsic to the learning and framing of knowledge."

This view led Tutor $\mathrm{C}$ to feel that by creating a new space she would give her students a better chance of expressing a line of thought in a more specific way than by leaving them to pursue a thread in a bigger, less differentiated conference. Tutor $\mathrm{C}$ also set out to separate process from content, by creating a preparatory conference for each Block where students could clarify process issues. She felt that this structure was consistent from Block to Block, although the level, number and names (such as preparation, meeting hall, general) of these process-oriented conferences varied. She subsequently found that these 
conferences also tended to develop a more café-like flavour, and this is discussed in Section 4 below.

While Tutor $\mathrm{C}$ commented that her idea of a bad conference space was one that was empty, containing few or no messages, this applied only to the spaces intended as interactive areas and her portal conferences quite often contained only a small number of messages, and those mostly from her. Tutor D was also fairly strict about keeping the top level for messages associated with her administration and weekly update messages to help keep students on track. She was even prepared to move messages from this area if she felt they were spawning a thread in a different direction. Tutor E, on the other hand, very much wanted to avoid circumstances in which message moving might be needed. Her much simpler structures reflected a desire to avoid situations in which students might be inhibited by wondering whether they were doing it right or agonizing about where the appropriate place was for a particular message. A prime consideration for her was therefore to have the minimum workable number of conferences, with every conference pulling its weight by attracting a substantial number of messages.

Tutors found that it could be a mistake to predict the final shape of learners' work on a task and lock that in to a structure. It was also very difficult to predict the numbers of messages that might be generated. As noted in respect of Figure 4, in Tutor Group E the two teams, each of 6 students, produced a total of 565 messages associated with activity 2 of Block 1. In Tutor Group A the two teams, each of seven students, generated a total of 274 messages for the same activity. Some tutors were naturally more inclined than others to adopt a shape-as-you-go policy by creating extra conference spaces even in the middle of an activity, while others felt that their response to the needs of the group tended to be more at the message level than at the structural level.

While tutors had the privileged status that allowed them to edit, move, or delete messages, they found that retrospective attempts to reshape the conference structure once it was in use could cause difficulties. Any message that is moved or archived into a separate conference or folder is automatically re-dated and automatically acquires the red flag that signals unread. Any previously created hotlinks to it become invalid. Some tutors felt more strongly than others that the conference record was the property of the group and should be not be tampered with by the tutor.

The fact that, by and large, the tutors alone shape the environment sparked considerable discussion. Tutor $\mathrm{C}$, from her perspective of seeing the conference structures as part of the cognitive organisation of knowledge, commented that: "collaborative learners [can't] move from peripheral status to expert status if they are powerless to shape group thought by modifying the structures which frame the group thinking," and felt it was a pity that such shaping by the students was so difficult to achieve in the FirstClass environment.

Tutors variously discussed with their group the roles individuals might play in particular activities or the topics they might investigate. Some also occasionally negotiated about what conferences might be appropriate, and Tutor $\mathrm{C}$ even solicited input into the choice of conference names and icons. However, attempts to address this question of ownership by allowing the students to control even a limited part of the structures were not successful. Tutor B set up subfolders as requested by the student moderator of one of the early activities, and gave that student the privileges to move, edit, and delete messages. She reported that this proved a salutary experience for that team of learners as they discovered the system drawbacks outlined above and also realised they could no longer find messages because they each had different expectations of where they might have been re-filed. Tutor D also acceded early on to students' request for an archive conference, to file away messages that were related to discussion process rather than to the topic, but noted that the request was never repeated for later activities. Tutor A asked students 
to justify their requests for additional conferences (which sometimes arose because they had seen such conferences in another Tutor Group); he then created the extra areas, only to find that not all of them were actually used.

\section{Creating a usable resource}

The assessment tasks for this course require students to reflect on their collaborative experience and to quote appositely from the conference record in order to support their arguments-sometimes many months after the conclusion of a particular discussion. Retrieval is therefore a major issue for tutors and students alike. It is clear that the retrieval of information is strongly dependent on an ability to locate particular messages in a record containing thousands of messages, and it was generally agreed among the tutors that there was a logical connection between conference structure and ease of retrieval. Again, however, there was a lack of consensus about how best to promote speedy retrieval.

Structure is one way of trying to facilitate retrieval, with more complex structures potentially offering more contextual information to aid location and retrieval of a specific message. There is also a FirstClass search tool. This Find feature allows retrieval by contributor name, and by keyword or phrase (although there are no Boolean operators). It is possible to search all the nested structures with a particular conference - though not a subset of them-and even all the message texts simultaneously, although this can be quite a slow process. However, items retrieved in this way can be difficult to relate to the threading. In the context of the complex discussions in this course, it is also easy to miss significant contributions simply because they do not contain a particular word, even though their content relates to this term or idea. The tutors also recognised that there were many other factors involved in learners' retrieval of information from the conferences, such as memory, working methods, diligence at keeping notes during each activity, and so on.

Weaving and summary messages were regularly used by the tutors as ways of both re-focussing on-going activities and laying a trail of signposts for students subsequently trying to retrieve the main substance of the discussion. The difference between weaving and summarizing is clarified in Cox [8], although many tutor messages in this course had elements of both functions. This is probably because the course deals with complex issues, and threads of discourse become densely interwoven. The sheer number of messages meant that it was fairly pointless simply to use the system's Summarizing function (described earlier) to string together and archive all the messages in a given period of time such as a week. However, the tutors were conscious that in weaving they had to select an arbitrary number of connections to make and that these would not necessarily reflect the smaller, subtle points of the discourse. Acknowledgment of this sparked another debate about the extent to which students at this level should rely on the tutor to provide this kind of signposting. Several tutors felt that the learners did indeed create their own routes and that in so doing signalled their ownership of the material generated within their own Tutor Group. The tutors' summarizing messages were therefore probably most useful in directing students to the main issues of a topic, and in orienting those super-lurking in a group other than their own. Tutor $\mathrm{C}$ noted that by putting hotlinks to these key messages in a portal conference she could create a partial index to the work going on in the nested structures.

The tutors were all agreed that the greatest barrier to easy retrieval was the poor use of message subject lines, compounded by repeated use of the reply function. Division of the space used for an activity into several different conferences areas was seen as one way of mitigating the problems to some extent, but it was also recognised that this could lead to the creation of more complex structures than might otherwise be the case. 


\section{Developing a social dimension}

The Plenary area contained a café for the use of all the students on the course, but tutors were free to construct social areas for their own group as well. The ways in which they went about this were noticeably varied, so a question was asked about the extent to which their individual views on the social interactions were reflected in this diversity. The responses showed that the issues involved were quite complex.

From the outset, tutors A, B and C created social areas for their own groups at level 1. Tutor A explained that he saw this area as "a coffee room within a department" and the café in the Plenary as "the Canteen that serves the whole institute":

The Canteen can give a sense of course bonding and interchange, but the café in my group was for initial group bonding away from the activities. I expected it to function mainly at the beginning and serve its purpose by the end of Block 1 or the beginning of Block 2 .

Tutor D also soon felt the need for a similar area:

The pub was created towards the end of some of the introductory activities that had encouraged some discussion of social issues. I felt that I needed to draw the introductory activities to a close, but provide somewhere for the social support to continue.

Tutors $\mathrm{C}$ and $\mathrm{D}$ echoed the comments about rates of usage of these level 1 chat areas decreasing with time.

Tutor $\mathrm{C}$ set out with just a café at level 1, but later archived some messages from this café into a level 2 area called 'bar,' and then found that too was occasionally used for chat. She also found that the conferences set up for each Block to discuss process tended to develop a "catch-all" element, becoming

typical café-like conferences ... used for talking about projected absences, holidays and anything else, often personal chit-chat, that wasn't work related . . purely personal, supportive stuff as well as disagreement, is in fact mostly concentrated there.

In other tutor groups, this kind of information was also usually posted in café areas or in conferences related to particular activities. Tutor E, however, took a different approach, creating an area at level 1 called 'Our Group' specifically for group members to use throughout the course to warn others if they were going away or were for other reasons going to be absent from the online community for any length of time. However, Tutor E deliberately did not create any purely social areas, and explained the reasons for this as follows:

[A]s most students struggle with the sheer volume of course related messages I was reluctant to create an area within my Tutor Group specifically for chat. This view was coloured by the fact that last year I did have a social area which didn't get many customers, and I vaguely assumed that numbers who wanted to participate (only a subset of those in the TG) did not constitute a critical mass, especially when the activity conferences got really busy. I do realise that some students will want to coffee-house, but I felt that the Plenary café provided a place for that, and that the larger number of students involved would mean that it was more likely to take off and therefore to provide a lively social arena." 


\section{STUDENT PERSPECTIVES}

\section{A. Methodology}

A combination of methodologies was used to probe the students' online behaviour, their attitudes to the conference architectures, and their reaction to the diversity of structural practice in different groups. One problem to be overcome in seeking feedback on the conferences was that the conferencing environment was not the same for all students. Their experience depended on a combination of factors: their method of access (FC client, FC Personal or web access), the set-up in their own Tutor Group (such as the architecture of their virtual Tutor Group spaces and the ways in which they might have been split into smaller teams for some activities), the nature of the interactions within the group, and the extent to which they use super-lurking in other Tutor Groups as a real learning strategy.

1. Interviews. It was felt that questions relating to the more complex issues of conference structure and its effects should be sought in (telephone) interviews. All those interviewed were asked the same questions, but the format allowed for clarification of terminology and for context setting, ensuring that interviewees appreciated the exact nature of the issues on which they were being asked to comment. The questions were piloted with one student and slightly modified as a result. Some examples of questions were:

- How easy was it to find your way around the various conferences/sub-conferences in your own tutor group area? Were you always clear where current work was being done? Were you ever unsure where the most appropriate place was for a message you wanted to post?

- How easy was to find your way around the various conferences/sub-conferences in other tutor groups? Were some group areas easier to penetrate than others, and, if so, why?

- What kinds of strategies did you use to find appropriate material from the conferences to use in your assignments? What sort of material did you want? How did you set about finding it (or did you save it as you went along)?

Ten students were then selected for interview, on a random basis designed to include two students from each Tutor Group, a 50:50 male-female ratio, at least two students not based in the UK or Ireland and some students known to be super-lurkers. Each interview lasted about 45 minutes.

2. Evidence from students' messages. As information technologies in education are the subject of the course, students naturally discuss the conferencing environment as part of their reflection on the experience of learning. Such messages can be very revealing of students' primary concerns. There was also a feedback conference in the Plenary area which received a few specific comments about the nature of the conferencing system.

3. Evidence from assignments. A question in one of the assessed assignments asked students to discuss the functionality of the FirstClass environment. Comments about the nature of their learning experience were also pertinent in answering other questions at various points of the course.

4. Online questionnaire. A parallel project involving an online questionnaire for all $66 \mathrm{H} 802$ students investigated students' use of printed and other electronic materials; two-thirds of the students returned these questionnaires. A question about the way in which people sorted and stored relevant information from the conferences was included in this questionnaire, mirroring similar questions about their handling of information from print and websites.

The issues identified by students are presented here under the same four fundamental themes that united the top concerns of tutors: 
- navigating the spaces

- engaging with the discussion

- using the record as a resource

- making social contact

These four themes relating to the student experience are expanded below.

\section{B. The student experience}

\section{Navigating the spaces}

Asked how they would retrospectively characterise the conference structure for their own tutor group, interviewees gave generally positive descriptions, such as "very/pretty logical layout," "the structure is fairly clear," "self-explanatory," "reasonably well organised," and "functional." One student commented "there is nothing that's superfluous there," in relation to a set of structures that could be classified as intermediate in complexity. Those interviewed could not recall any great upsurge of demand for an alternative conference structure from that which their tutor put in place before the beginning of each Block, although one did comment how being struck by the amount of control the tutors had exercised over the appearance of their group area.

The opinions of the students about whether they preferred simple or complex structures were quite sharply divided. One interviewee appreciated the fact that there were not too many levels of conference in her group, saying "all the messages would be there in one folder." Another put forward the view that the fewer conferences there were, the better-if time was an issue then it was important to know exactly where to go. One student expressed a preference for "a smaller number of conferences with a high number of messages in each" rather than a proliferation of conferences each with a smaller number of messages, but-interestingly, given that he was Tutor Group $\mathrm{C}$, the one with the most complex conference structure-concluded that the balance in his own group area was just about right. Students who had the opposite preference also used balance as a criterion: another group $\mathrm{C}$ student commented that "there always seemed to be a tension between too many conferences, yet not enough conferences to reflect the debate as it went on."

Some saw this as a workload issue, with one student writing in their first assignment of the possibility that the creation of a plethora of conference spaces brought with it the danger of overload, which might in turn lead to students accessing only a proportion of the conferences. For the same assignment, another student wrote about the way that having to drill down though the conference levels rapidly created task bar clutter. In his opinion it was up to the tutor to control the number of conferences to ensure that this clutter did not inhibit learning.

Practices in online conferencing were the focus of a short, plenary seminar conference about halfway through the course, with Michael Morgan as guest leader. In this seminar, students commented that they had noticed distinct differences in online tutoring styles among the five tutors in terms of conference layout (i.e. structure), and also in relation to the amount of negotiation the tutors undertook about roles and topics for the activities, and the numbers of messages they posted. When asked specifically asked about their experience of super-lurking in other groups, interviewees talked about discovering that other groups had been "set up differently". They found it less easy to find information when they had not been "a part of that setting up" and were not familiar with the evolution of the structures. One learner used to the complex structures of Group C said that going into other tutor groups was "a nightmare": it was 
impossible to work out what was going on. In contrast to this, a student from Group A reported "no problems finding out what was happening in [other] groups and which area was the most up-to-date". However, many were aware of the problems of missing context when entering other groups' spaces.

The plenary areas proved relatively easy to navigate. Four interviewees were positive about the structures of these conferences, saying that the Plenary was "straightforward," the structures were "fine," they "knew exactly where to go, so it was easier to pick information out quickly," and that the structure was "very simple, a lot simpler" than that within their own tutor group. For two others, the Plenary was not as user-friendly as their tutorial group and could be "cumbersome"; they saw these difficulties as arising mainly from the fact that the plenary areas involved too many people and too many messages.

In terms of knowledge-building and collaborative effort, all the structures created by the tutors were generally deemed satisfactory and what was seen to matter most was the discipline and focus of the users. One interviewee used the descriptor organic for the conference structures, because of the tendency for discussion to drift or to stray off topic and "clog up conferences". One student noted that members of her group had been overwhelmed and confused early on, finding it difficult to follow conversations because of the number of threads. When she was appointed moderator for an activity she had therefore tried to limit the number of threads, but recognised that some people might have been put off by this approach.

\section{Engaging with the discussion}

The way in which the students used the conferences was a major focus in the online seminar discussion. While some students' approach was very systematic and that of others was more casual, all were agreed that their first priority was reading and responding to messages posted to Tutor Group conferences and specifically related to the current task. If there was time, some then moved on to other tutor groups and social areas. They checked to see which conference(s) had new messages, usually looking first for replies to their own messages, extensions to particularly interesting threads, and messages from the tutor. Several students commented that in order to follow a thread it was often necessary to read complete sequences of messages in the order in which they had been sent.

At the time of the seminar conference, most students reported reading all the messages within their Tutor Group area, although in other areas they selected messages more casually, for example on the basis of names they recognised (perhaps someone who had had interesting things to say previously) or catchy titles. By the end of the course, only about half the interviewees were still reading everything. Language and length were most often mentioned as the reason for not reading messages. Four of the eleven interviewees said they were put off reading messages if they were very long, or written in a very academic, jargon-ridden or highbrow style. Messages that were perceived as content-free-usually from people who said little more than 'thanks for that,' 'don't mention it,' or 'yes, I agree'-were also mentioned as irritating and likely to be screened out.

\section{Using the record as a resource}

Most students found that posting to conferences was relatively easy, but many discovered that subsequently managing messages was more difficult. This was exacerbated by the fact that at the beginning of the course students had not necessarily fully appreciated the extent to which messages would later become a major resource. Several interviewees said that in retrospect they felt they needed (possibly different) strategies for conferencing and for resource management. It is difficult to make a clean distinction between academic strategies and technical strategies, and in some instances the two are very closely intertwined. Many of the students appeared to have strategies not only for finding, but also for 
saving and organizing messages. Data collected via the online questionnaire shows that $93 \%$ of respondents printed out conference messages (sometimes or frequently), 68\% kept a record of the conference location of important messages, and 66\% copied messages, or parts of messages, to another computer file. Some respondents also wrote notes on paper $(63 \%)$ or typed notes on their computer $(41 \%)$ when reading conference messages.

For at least one interviewee, there was a tension between keeping track of references and participating in online activities; other students also commented that the relentless way in which the conference messages built up meant organisational tasks were often done in arrears and needed to evolve frequently, which in practice meant they were often abandoned in favour of more pressing tasks.

In using the conferences to inform students' planning for assignments, three types of strategy could be distinguished:

(1) an early bird strategy of steady collecting, using a special file

(2) an iterative or two-step process of collecting during the activities, and again just before writing the assignment

(3) a just in time strategy of trawling as they composed their assignment.

One student reported being able to use the structure of an activity conference directly in their assignment, with the threads becoming the essay headings, but most students found that collecting information to use for assessed work was a major task. While at this stage in the process the majority of students were hunting for specific evidence or information to support their own arguments, some might still be reviewing themes and ideas. The interviewees who adopted strategy (1) had developed systematic approaches to building their own searchable (Word or Internet Explorer) resources, using cut and paste methods. However, many others focussed on the fact that this kind of organisation could not be done within the FirstClass system and did not attempt it in another application. A number of students clearly wanted to be able to mark, reorder-and even delete-messages within their personal view of a conference, and to annotate other peoples' messages. It was also interesting that many appeared to rely more on memory of particular threads or messages than on the Find system tool for searching the conference record.

\section{Making social contact}

Students from all groups participated in the café in the Plenary area, and some commented that this gave them a link with students in other groups which they considered to be valuable. The fact that Group E was the only one without a purely social space of their own was raised by one of the students in the Plenary area and led to considerable cross-group discussion. Typical of the reaction of those in other groups was that their own group's informal area was somewhere they could drop into "when the business was done," though they would sometimes find no one else was there. However the students in group E who joined this discussion said they had had sufficient social contact without a specifically social space and felt they had developed a good rapport simply by working together. Course culture was one in which mutual support featured very strongly, especially when individuals had difficulties or low points, and this culture was evident in every group. In group E this overt support necessarily took place only within the taskbased conferences and one of the students in this group wondered whether it was in any case

artificial to draw so clear a distinction between professional and/or academic and social interaction. Indeed, creating distinct rooms suggests that we ought to compartmentalise our interactions. . . . Is it not better for interactions to be complex, and for conferences to simply represent clear time/topic distinctions, but include all possible types of interaction? 
A student in group D wrote in similar vein an assignment that, in her view, the separation of the social aspect of interaction from ongoing tasks meant there was a danger of it being perceived as unimportant.

Even when they had a separate group area for socializing, students still gave considerable emphasis to the social cohesion and support element within the task-based conferences. A discussion in the seminar conference about the types of messages that prompted responses drew many comments of the type: "I respond to ... requests for help immediately if I can"; "when people sound dispirited I know it's great to get a reply, so I try to respond then"; "I try to thank people for help and/or to acknowledge someone's hard work on all our behalf (in collaborative tasks) —it seems the least you can do!"; "I respond to [questions] if I can because I appreciate a response to my own musings; deadly silences unnerve me"; "if someone has put in a message and no one has responded to it, I try to say something so it isn't just left hanging." Similarly, individual threads within the academic discourse were affected by social aspects, with many people saying they were more likely to respond to messages from people they liked and from those who were not overly assertive.

Whether they frequented the cafés or not, it was clear that the students developed their best sense of what their peers were like by working with them. One commented that the group members she felt closest to, and to whom she could respond most easily and most positively were those from the team in which she worked initially. She felt that "opening the conferences to larger and larger numbers seems to depersonalise the experience as you adjust to the different ways individuals express themselves and react to your own messages". Perhaps this was why the Group E students hardly availed themselves of the opportunity for socializing in the Plenary café, even though they had no café in their own group area.

\section{DISCUSSION}

Although a planning model might suggest that learning environments should be built from the top down, with philosophy determining higher level pedagogy, strategy deriving from higher level pedagogy, and tactics deriving from strategy, Goodyear [16] notes that the relationship between the operational layers in particular is not always so straightforward:

$\ldots$ it is not uncommon to find strategy which is really emerging from tactics-thus strategy becomes a way of describing the common threads woven by intuitive tactical activity.

A continuous sub-text in the discussions among the tutors was the extent to which such emergent strategy arose from the ways in which the FirstClass system itself dictated the structures of the conference environments. Many pedagogic concerns focussed round the nature of the FirstClass environment and its suitability for sustained discussion and argumentation. The system is essentially a development of one designed primarily for e-mail, so for messaging it is fast and robust. However, layered architecture within its conferences can be hard to visualise and to navigate. Also, as noted by Hewitt [14] in relation to threaded discourse generally, its default threading hierarchies make it less good for discussion requiring synthesis and convergence. This problem was exacerbated by poor use of subject lines and over-use of the reply default by many students. The thread format is the only available visual overview of an evolving discussion; if the subject lines do not reflect the content of individual messages, the relationship between them and the evolution of the discussion, then there are few contextual clues and it may be difficult to retrieve key messages at a later date.

On the other hand, this study certainly did not support the suggestion that computer conferencing can lead to "a downward spiral in the caliber of discussion" or that it necessarily "has limitations in sustaining dialogue momentum through several rounds of responses," as summarized by Foley \& Schuck [17]. The 
Masters level students on this course were clearly able to develop discussions involving long threads (20 or 30 messages per thread were not uncommon), in contrast to the Level 1 undergraduates surveyed by Cox [8] whose conference discussion averaged only 2.3 messages per thread. And although many of the students felt that that they did not have very developed strategies for participating in, and storing information from, the conferences, they did in fact adopt quite sophisticated tactics, almost unanimously giving priority to task-focused messages while engaged in online discussion.

Conference navigation also proved less of a problem for these students than might have been anticipated. In relation to the FirstClass environment, Cox [8] pointed out that "students cannot quickly see the relationship between the different sub-conferences [so] the sense of fragmentation needs to be minimised by the tutors." From this they developed a recommendation that "tutors should be discouraged from creating overly complex structures within their conferences" regarding this as important mainly because "in a complex structure people have a hard time working out where to send which messages. The total volume of messages gets spread more thinly. Everything looks like there isn't much interest, so people feel more exposed and are less likely to post." Perhaps because of the difference in level between the course examined by Cox et al. and the one discussed here, their recommendations seem inappropriate and certainly there was no evidence of the volume of messaging being linked to structural factors. The audience for the posting was a much more significant factor, but evidence from the interviewees suggested exactly the opposite proposition to that put forward by Cox: in this Masters course if there were only a relatively small number of people working in an area, students felt they could post a message even if they were not absolutely confident about it. They were more apprehensive about posting in Plenary areas where the numbers of participants were potentially higher. Similarly, recommendations from Salmon [7] that course moderators should "summarise, delete or archive messages so that no more than around 20 messages in any one conference or sub-conference are active at any one time" were clearly not appropriate for a conference environment in which tens of messages could be posted daily but reflections within threads could extend over days or weeks, and for which the original conference record was regarded as an important resource.

Although there was a clear attempt by certain tutors to frame the conceptual organisation of the discussion by creating a particular structure for some of the collaborative knowledge-construction tasks, this was not always the reason for creating a new conference and tutors also had personal styles in conference creation which had little to do with pedagogy. Cox [8] commented on possible gender differences among tutors, finding in their study that female tutors tended to create more sub-conferences, used visual markers more freely, and had more non-linear structures. Our study does not bear this out, but was carried out on a far smaller number of tutors, with an uneven gender distribution. Most of the tutors seemed to have a basic structural formula and stuck with it throughout the course. Only one tutor had a different de-layered structure in the first block of the course to the architecture she used in later blocks. Subsequently there were comments from both tutors and students making arguments for simple structures and fewer conferences at the beginning, building up to more complex ones later once the learners were more accustomed to the environment. However, such arguments need to be balanced against the complexity of the curriculum and activities in the different parts of the course.

Students' archiving and retrieval strategies were quite well developed although those who did not make their own archives during the discussion often found it difficult to locate messages at a later date. While some tutors went to great lengths to create contextual clues by nested structures of sub-conferences, we found no compelling evidence that students made any logical connection between structure and retrieval. They all found the structures within their own group areas clear, but varied in their reaction to the structures in other groups. Those who reported few difficulties with retrieval of information in their own group conferences may have been using structures to help them recognise message location, but it may 
simply have been that they were very familiar with these conferences. Certainly memory of particular messages did play a key role in many students' retrieval strategies. Even if the conference structure had been intended to provide contextual clues, individual messages might be hard to find within that context, perhaps because of misleading subject lines. The search facility of FirstClass might also be used to track down a message, bypassing structures entirely, though most students did not make great use of this facility.

The social aspects of interaction are widely recognised as important in providing continuing motivation and what Cox [8] have described as social cement for an online community. All the students who commented on this issue agreed that they had greatly benefited from the support and encouragement of peers, especially in times of difficulty, although there was no consensus about whether it was desirable to have a structure with separate café-type conferences. Where these conferences were created within tutor group areas, they were quite well used in the early stages, with usage tailing off within a month or two. This is in direct contrast to the behaviour of the students observed by Cox, who made little, if any, use of such areas. However, it is clear from the comments students made about what prompted them to respond to messages, that a great deal of mutual support and social maintenance did go on in the task-related conferences and students in the one group without any separate chat areas felt that support and socialisation was readily available within the activity conferences. This is the opposite behaviour to that observed by Curtis \& Lawson [6], who in their study found no evidence of what they called off task activity among students. Bonk [18] did see low levels of such activity, but singled out as unproductive the kinds of messages they described as social acknowledgements, messages that the students here also tended to skip.

\section{SUMMARY AND CONCLUSION}

We have described an investigation into a conferencing environment that explored the perspectives of both tutors and students, seeking to discover and understand their priorities and behaviours, and shedding light on the learning practice of students as a response to a particular online learning architecture. The investigation has shown that the tutors made assumptions about students' likely access and navigation methods, but did not try to predict the final shape of learners' work on a task or to lock it in to a rigid structure. Tutors showed awareness that their design decisions might have an effect on students' cognitive activity, although students were not especially conscious of this. Students generally found the conference structure for their own tutor group to be logical, self-explanatory and functional. However, outside of their own group, it was sometimes less easy to find information. Tutors also recognised that retrospective attempts to reshape conference structures could cause difficulties for students, and students who made experiments in this direction concurred.

Students' first priority was reading and responding to messages posted to their group conferences and specifically related to the current task. As time went on, they became more selective with regard to the messages they were prepared to read; language and length became the main reasons for screening out certain messages. Students also realised gradually that managing messages as a resource was difficult. At the beginning of the course, they had not fully appreciated that messages would become a major resource, and only later did they feel they needed specific strategies for resource management. Students displayed a range of strategies when using the conferences to inform their planning for assignments.

Tutors were aware from the outset of the issues surrounding resource management and retrieval. They saw logical connections between conference structure and ease of retrieval, with complex structures potentially offering more contextual information. However, there was little evidence that students made such direct connections and their retrieval strategies relied more often on memory than on structural clues 
or system tools. There was therefore a lack of consensus among the tutors about how best to facilitate retrieval of useful material. All tutors did agree that the greatest barrier to easy retrieval was in fact the poor use of message subject lines. There was less agreement about the extent to which students at Masters level should rely on the tutor to provide signposting within conferences, and a feeling that learners creating their own routes resulted in positive ownership of the conference material.

Tutors were generally keen to promote social interaction, with all providing a place for notifications about absence and most also creating areas purely for chat. However there was an awareness that too many social messages could hinder retrieval of more vital information and could increase the workload for students. Students saw their informal group areas as places where they could drop in after work, and the Plenary gave them a valuable link with students in other groups. On the other hand, some students felt that they could have sufficient social contact without a specific social space in their group, developing a good rapport simply by working together. Even when they did have a separate group area for socializing, students still gave considerable emphasis to the social element within the task-based conferences.

The investigation has shown that at the strategic and tactical levels, tutors have to be very aware of how students operate within the online environment and how they access conference messages. The tutors involved in this study were experienced teachers and already knowledgeable about many aspects of online learning. For them part of the satisfaction in tutoring this course was the relative freedom to set things up their way. Nevertheless, as a result of this project they have gained a new appreciation of some of the nuances.

\section{ACKNOWLEDGEMENTS}

Three of the authors were tutors on the course. We are very grateful to the other tutors, Carol Higgison and Sarah Cornelius, both for permission to use their conference records as case studies and for their contributions to the discussions that led to this paper. We are also indebted to the many students who have shared with us their experiences and views of online learning.

The student interviews were undertaken by Simon Rae, to whom we extend our thanks.

FirstClass $^{\mathrm{TM}}$ is supplied by SoftArc/ Centrinity.

\section{REFERENCES}

1. Thorpe, M. Rethinking Learner Support, the Challenge of Collaborative Online Learning. Open Learning 17(2): 105-119, 2002.

2. Tait, A. Student Support in Open and Distance Learning. In: Lockwood, F. (Ed.), Open and Distance Learning Today. London: Routledge, 1995.

3. Jones, C. Evaluating a Collaborative Online Learning Environment. Active Learning 9: 31-35, 1998.

4. Noakes, N. Collaboration and Community Constituents: An Investigation into the Key Elements that Build, Nurture and Sustain a Collaborative Learning Community in Networked Spaces. Online Paper, Fourth Annual TCC Online Conference: Best Practices in Delivering, Supporting, and Managing Online Learning, 1999. Available online:http://leahi.kcc.hawaii.edu/org/tcon99/papers/noakes.html.

5. McKenzie, W. and Murphy, D. "I hope this goes somewhere": Evaluation of an Online Discussion Group. Australian Journal of Educational Technology 16(3): 239-257, 2000. Available online: http://www.ascilite.org.au/ajet/ajet16/mckenzie.html. 
6. Curtis, D. D. and Lawson, M. J. Exploring Collaborative Online Learning. JALN 5(1): 2001. Available online: http://www.sloan-c.org/publications/jaln/v5n1/v5n1 curtis.asp.

7. Salmon, G. E-Moderating, the Key to Teaching and Learning Online. London: Kogan Page, 2000.

8. Cox, S., Clark, W.P., Heath, H. and Plumpton, B. Key Facilitation Skills for Effective Online Discussion Groups: Herding Cats through Piccadilly Circus. Paper presented at Competition, Collaboration, Continuity, Change: Distance Education-An Open Question? University of South Australia, Adelaide, 11-13 September 2000. Available online: http://www.com.unisa.edu.au/cccc/papers/refereed/paper11/Paper11-1.htm.

9. Goodyear, P. Environments for Lifelong Learning, 2000. Available online: http://soeweb.syr.edu/Faculty/Spector/courses/Ide-714/Notes/goodyear-28Jul00.pdf.

10. Goodyear, P. Psychological Foundations for Networked Learning. In C. Steeples and C. Jones (eds.), Networked Learning: Perspectives and Issues. London: Springer, 2002.

11. Cicognani, A. Architectural Design for Online Environments. In B. Kolko, Virtual Commons: Policy and Community in an Electronic Age. New York: Columbia University Press, 2002.

12. Putz, P., Arnold, P. Communities of Practice: Guidelines for the Design of Online Seminars in Higher Education. Education, Communication \& Information 1(2): 2001.

13. McKenree, J., and Mayes, J.T. "The Vicarious Learner": Investigating the Benefits of Observing Peer Dialogues, 1997. Available online: http://www.media.uwe.ac.uk/masoud/cal-97/papers/mckenre.html.

14. Hewitt, J. Beyond Threaded Discourse. International Journal of Educational Telecommunications 7(3): 207-221, 2001. Available online: http://www.aace.org/dl/index.cfm/fuseaction/View/paperID/6473.

15. Kear, K. Following the Thread in Computer Conferences. Computers and Education 37: 81-99, 2001.

16. Goodyear, P. Pedagogical Frameworks and Action Research in Open and Distance Learning, Ref 99041: 1999. Available online: http://domino.lancs.ac.uk/edres/csaltdocs.nsf.

17. Foley, G. \& Schuck, S. Web-Based Conferencing: Pedagogical Asset or Constraint? Australian Journal of Educational Technology 14(2): 121-140, 1998. Available online: http://www.cleo.murdoch.edu.au/ajet/ajet14/foley.html.

18. Bonk, C. J., Malinowski, S., Angeli, C. \& East, J. Web-Based Conferencing for Pre-Service Teacher Education: Electronic Discourse From the Field. Journal of Educational Computing Research 19(3): 269-306, 1998.

\section{ABOUT THE AUTHORS}

Dr. Shelagh Ross is a senior lecturer in the Department of Physics and Astronomy at the Open University. She is one of the tutors referred to in this paper. Her main interests are in the field of science education: students' representations of physical situations, problem-solving strategies for physics learners, and teaching science at a distance and in virtual environments.

Dr. Agnes Kukulska-Hulme is a senior lecturer in the Institute of Educational Technology at the Open University. She was the Course Team Chair for the course at the time this project was undertaken. Her research interests are centred on user interface design and pedagogical usability, and the evaluation of technologies for distance learning.

Helen Chappel is an experienced constructivist educator with multiple, globally distributed, instructional roles. She is a graduate of the Open University's MA in Open and Distance Education and one of the tutors referred to in this paper. She works between Athens and the UK, and is currently pursuing postgraduate research at the Scottish Centre for Research into Online Learning and Assessment (SCROLLA). 
Brian Joyce is an educational technologist. He is a graduate of the Open University's MA in Open and Distance Education and one of the tutors referred to in this paper. He is currently examining the diversity of issues that contribute to mobile learning, especially in English language learning at his language school, LSC-Opisto in Tampere, Finland. 
JALN Volume 8, Issue 2 - April 2004 